\title{
Space Research and Mini-satellites in Secondary High School
}

\author{
Mária Pető \\ Science Department, "Székely Mikó” High School, St. George, Romania \\ Email address: \\ rkollegium@yahoo.com \\ To cite this article: \\ Mária Pető. Space Research and Mini-satellites in Secondary High School. International Journal of Astrophysics and Space Science. \\ Vol. 5, No. 5, 2017, pp. 71-78. doi: 10.11648/j.ijass.20170505.11
}

Received: August 9, 2017; Accepted: September 13, 2017; Published: November 16, 2017

\begin{abstract}
Space research, the universe and satellites are three fascinating questions to which students have no possible answers in the regular school curriculum. Therefore, every opportunity to bring these topics into school activities and closer to the students' interest is welcome. The European CanSat competition held by ESA (European Space Agency) presented itself as one solution for meeting this demand. CanSat is a minisatellite that can be fit into a Coca-Cola soda can (330ml) and it is released from $1 \mathrm{~km}$ altitude. This mini device is based on Arduino- microcontroller and it performs certain scientific missions like measuring air pressure, temperature, humidity, dust pollution, radiation level, location, telemetry, etc. This competition and the preparation period are useful for students as they offer a special opportunity to learn about sensors, microcontrollers, radio communication, space research missions, project management. Furthermore, they help the development of technical skills and applications of the acquired theories.
\end{abstract}

Keywords: CanSat, Minisatellite, Arduino, Education

\section{Introduction}

The present paper would like to present one of the results of teaching extracurricular activities in Székely Mikó High School (St. George, Romania), during which the author attempted to attract students to sciences, to maintain their initial curiosity, to arise their interest in new applications of physics, in modern technologies and research. New methods and approaches have been applied that lead the curious towards interdisciplinary subjects such as astronomy and space research, and help students who learn "Sciences" as part of the national curriculum.

The aim of this project is that in the course of building the mini satellite students will become acquainted with the world of sensors, learn about their operation principle, and broaden their knowledge in the area of electronics. At the same time, the students' technical skills and knowledge will be developed, which is mostly impossible in the course of regular lessons. The use of the Arduino board makes it possible to combine the knowledge acquired during Physics classes with IT (Information Technology) skills and technical challenges. The whole process also helps the students to familiarize with the phases of a scientific project in a special area, like that of space research.

The CanSats (can-soda-satellite) are mini satellites placed in standard soft-drink cans $(330 \mathrm{ml}$ volume, $115 \mathrm{~mm}$ height and $66 \mathrm{~mm}$ diameter) which simulate the work of a real scientific satellite. The CanSat is required to have a weight between 300-350 grams, it must be able to work continuously for at least 4 hours, and it should have a safe recovery system and an easily accessible power switch. The maximum flight time is recommended to be between 120-190 seconds with a descent rate between $4,6 \mathrm{~m} / \mathrm{s}-11 \mathrm{~m} / \mathrm{s}$. In addition, the unit must be able to withstand acceleration up to $20 \mathrm{G}$ and a pressure of 40atm. During flight, it should be in contact with the ground station permanently and be transmitting measuring data. The total budget of the CanSat device should not exceed 500€. [5]. The CanSat is released from a rocket (Intruder type) or a light plane at an altitude of $1000 \mathrm{~m}$. During the fall, the minisatellite will perform various scientific missions and it is expected to land safely. The primary scientific mission is compulsory for every participating team, and it consists of measuring the air pressure and temperature. The secondary mission is chosen by the participating teams, for instance advanced telemetry, guided landing on a target, radiation level, etc. The European 
CanSat competitions are held by ESA. ESA member states take turns organizing national competitions and the winners will participate in the international contest. The final phase of this contest is organized at Andoya Rocket Range in Norway or in another ESA member state. During the whole competition, the students should write technical progress reports and edit design documents in English, which are regularly sent to the competition board.

The challenge for the high school students (aged 15-19) is to develop a scientific mission, like designing a real satellite and filling all measuring subsystems, communication, and power units into a small space, thus producing innovative scientific, technological and educational value and promoting their activity.

\section{Method}

Since the national curriculum does not contain almost any lesson regarding this topic, the whole work starts with preparatory studies to gain knowledge about the design and elements of satellites, and the various tasks they should perform. It is obvious that the $9-10^{\text {th }}$ grade high school skills are not sufficient for planning and building electrical circuits, designing and constructing control systems for satellites. In order to introduce them in this field, simplified circuit models are used to teach the role of semiconductor circuit elements, the operation principle of integrated circuits, sensors and microcontrollers. The next step is to learn reading and interpreting the sensor datasheet. In the next stage students design test circuits, simple units and test them, which are then converted into a controllable, well-structured system.

The understanding of the measurement principle is achieved in the following way: the students perform parallel measurements using analog measurement techniques (a barometer for pressure, thermometer, etc.) and sensors connected to the Arduino microcontroller. The fluctuations generated by the variation of sensors resistivity are used for the measurement and are "translated" as atmospheric data. The voltage or current fluctuations measured by the sensors are converted into digital signals by a corresponding command program and then are transmitted to the microcontroller. Later, these digital data are reconverted into real pressures and temperature values using a proper program. When a command code (program) is written, the temperature and pressure dependence of the resistance and its consequences for the measurements is defined. A calibration curve for each measurement and for each sensor is later drawn. To validate the measurement procedure the students use the local Atmospheric Quality Control station data and measurement procedures.

Different programs are used, such as MS Access, MS Excel and Wolfram Mathematica programs to process the data measured by the unit's sensors to help students familiarize themselves with the simple methods of computer data processing and learn how to draw and interpret diagrams and charts. With these, they examine and prove the validity of learned physical laws under realistic conditions.

The students have been participating in this competition since 2012 (figure 1). At the beginning, they were absolute beginners, as they did not know anything about satellite building. Therefore, they started from the basics. After a few introductive lessons about satellites and electronic sensors, a very simple but well-functioning measuring device was built which included pressure, temperature and dust sensors, a radio communication unit and a Yagi antenna. The antenna used by the team was similar to a Yagi-Uda array one. This antenna was a tuned one, at a frequency of $433 \mathrm{MHz}$. Three parachutes were designed for different weather conditions and the device was placed into a special homemade steel cylinder.

The main idea for the secondary mission was to improve the students' knowledge of atmosphere physics by verifying the barometric pressure formula and vertical temperature gradient law, as well as to complete an air pollution chart. It was chosen to measure dust density since the region is highly polluted relatively, as far as dust density is concerned due to the proximity of several factories. The main goal was to form a proper image of the situation and therefore increase public awareness of this phenomenon.

First, a detailed plan of the whole building process was made, then, the measurement device (hardware and shell). In the next phase, every single subsystem of the CanSat (the sensors, the radar, the GPRS - General Packet Radio Servicemodule, the RF -Radio Frequency- transmitter and the parachute) was tested separately. Finally, the CanSat was assembled and the whole system was tested. This part served as an overall simulation of the Launch Campaign.

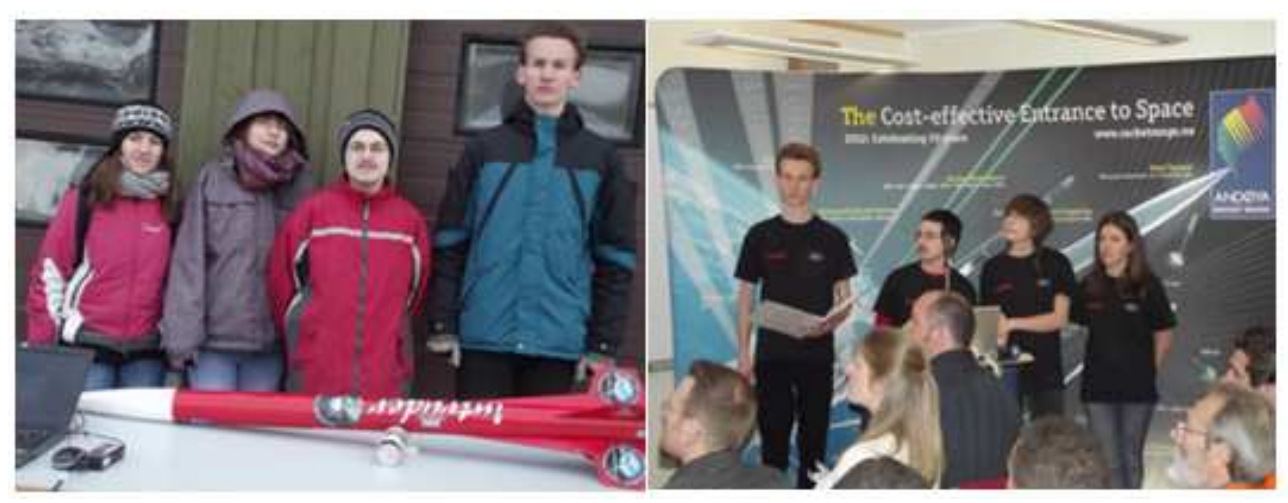

Figure 1. The "Bolyai" CanSat team (Andoya Rocket Range, Norway, 2012). 
During the launch campaign at Andoya Rocket Range, the initial goals were achieved:

a) the CanSat worked properly;

b) the parachute deployed properly;

c) good descent rate $(7.6 \mathrm{~m} / \mathrm{s})$;

d) no major damage at landing;

e) continuous radio communication between CanSat and ground station;

f) two sets of measuring data were collected and saved;

g) there were no significant differences between values measured in a defined height interval;

$$
p=p_{o} e^{-z \frac{g \mu}{R T}}
$$

The (1) exponential function (which was taught during thermodynamics lessons) helped students to compare the theoretical values with measured data and to calculate the maximum altitude of the Cansat. According to the calculations, the maximum altitude $(\mathrm{z})$ of the rocket and the Cansat at $8,5^{\circ} \mathrm{C}$ degrees was about 930 meters.

Based on the preliminary knowledge of the students [9], the obtained graph should have been an exponential curve. However, on the obtained diagram it seems to be linear (figure 2).

\section{Air pressure during the CanSat landing}

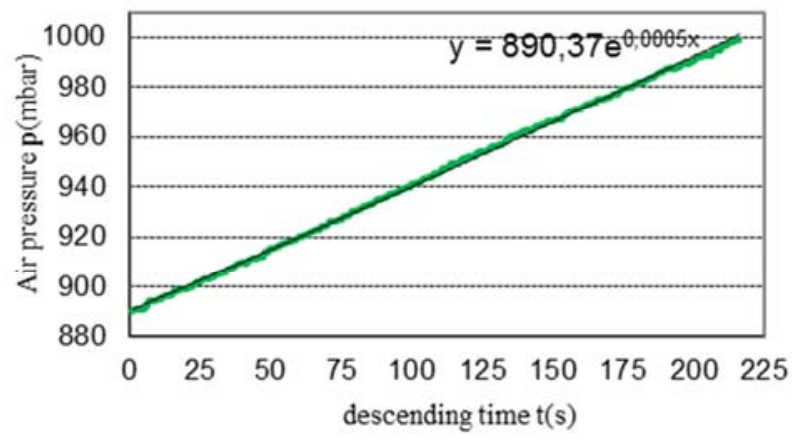

Figure 2. Variation of air pressure with altitude during the CanSat falling

To explain this result, we must note that temperature decreases in a linear way with altitude. The temperature gradient in the troposphere is:

$$
\frac{T-T_{o}}{z-z_{o}}=\frac{d T}{d z}=\alpha \alpha=-0,0065^{\circ} \mathrm{C} / \mathrm{m} ; \mathrm{T}=\mathrm{T}_{\mathrm{o}}-0,0065 \mathrm{z}
$$

Using the laws of hydrostatic pressure and ideal gas:

$$
\begin{gathered}
d p=-\rho g d z \text { and } p=\frac{\rho}{\mu} R T=\rho R^{*} T \\
\frac{d p}{p}=-\frac{g}{R^{*} \alpha} \frac{d T}{T}
\end{gathered}
$$

The equation that describes the pressure variation for the troposphere could be obtained from these conditions:

$$
p=p_{1} \cdot\left(\frac{T}{T_{1}}\right)^{\left(\frac{-g}{\alpha R^{*}}\right)}
$$

With: $\mathrm{R}^{*}=287,0583 \mathrm{~J} / \mathrm{kg} . \mathrm{K}$

$$
p=p_{1}\left(1-\frac{0,0065}{T_{1}}\left(z-h_{S}\right)\right)^{(5,252)}
$$

This result perfectly explains the obtained data: according to $(5,6)$ the pressure decreases in a linear way with the temperature. The readings from the pressure sensor corresponding to the pressure law, which describes the variation of air pressure with altitude (figure 2).

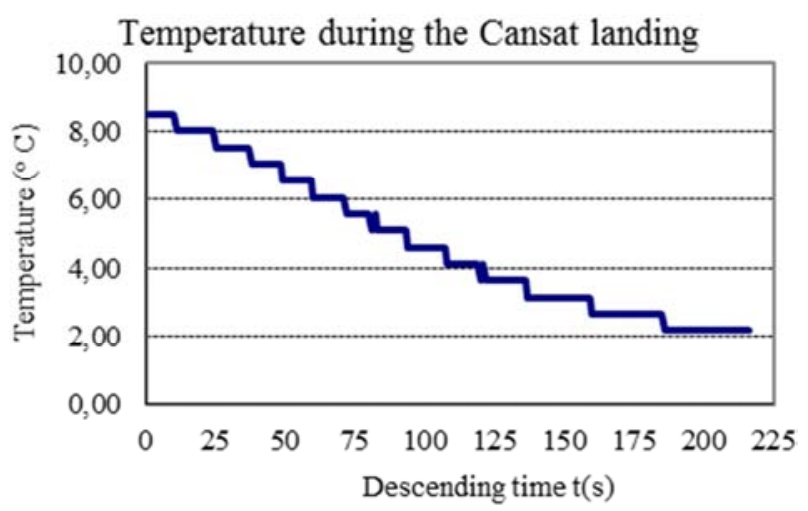

Figure 3. Temperature variation during CanSat falling.

The diagram in figure 3 presents the temperature data received from the Cansat throughout the descent. The diagram is linear and shows that the temperature decreases according to the inversed gradient law (2). Interestingly, the values are higher at high altitudes than near the ground. The explanation for this is the phenomenon of temperature inversion. This can happen when several factors coincide:

a) The sky was clear and the temperature was $1{ }^{\circ} \mathrm{C}$ during the night before the launch day, (22 April 2012). Due to this, the whole air cooled down, cooling down also the ground and the surrounding sea.

b) In the morning of the launch day (23 April 2012) dense clouds appeared at a $1000 \mathrm{~m}$ altitude, which reflected the sunlight and its heat, not allowing the Earth's surface to heat up. However, the low clouds absorbed the heat.

For the 2015 and 2016 CanSat contest, more complex and complicated devices were designed in which the previous experiences and knowledge were used (figure 5 and 8). These minisatellites complied with all the rules and standards of the CanSat competition and could perform special data analysis, by associating the data received with a $3 \mathrm{D}$ map, falling simulation and different dynamic and position measurements (figure 6). During the descent the unit sent measuring data to the ground with the help of a radio transmitter and uploaded the received information to a web server with a GPRS module. The collected data were analyzed and processed by students and the results were presented at conferences or used at physics classes.

In 2015 for the secondary mission, it was chosen to simulate the exploration of a newly discovered planet like a real satellite. Therefore, the mission was divided in two parts. First, the quality of atmosphere was determined by 
measuring the air pressure, temperature, humidity, different gas concentration and dust pollution. From the acquired data, it was intended to compile a vertical map of humidity, temperature and UV (ultraviolet) radiation intensity and a horizontal map of soil moisture levels. The aim was to get an accurate picture of the physical properties of the atmosphere and ground in order to determine whether these provide a possibility for life. It was important to see how accurate the data gathered with such measurement methods could be, and then adjust them accordingly.

The second task proposes to explore the surface of the planet with a small rover after the CanSat landing. This rover would then investigate soil moisture levels. For this task, a mini-rover was introduced into the CanSat that was deployed after the landing. The rover was a semi-autonomous vehicle, which was small enough to fit in our CanSat, and it had a soil moisture sensor (figure 4).

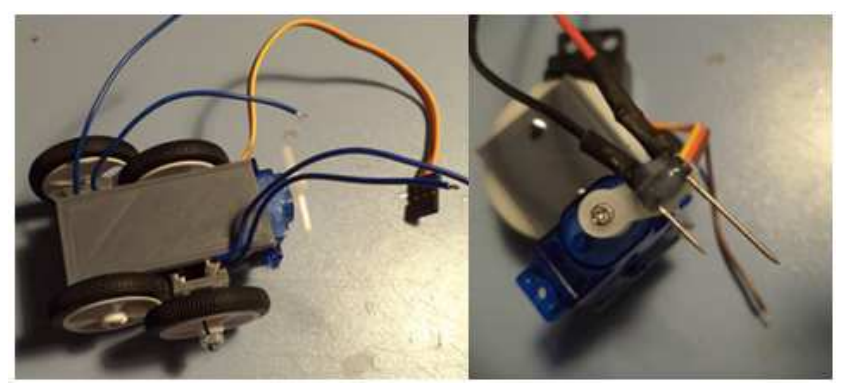

Figure 4. Rover and soil moisture sensor designed by the SzMK-team.

The rover was driven by two electric motors with two gearboxes and tracks. An Arduino unit based on the Atmel ATmega 328 microcontroller controlled the rover. All of the rover's components were held together by the main chassis, which was made of PLA (PolyLactic Acid). The ground receiver unit was entirely built by the team, based on an Atmel Atmega 328 microcontroller and the transceiver included in the CanSat kit.

Being aware of the problem of global warming, students are taught its special aspects in the region, since the town has an individual microclimate, for which the national meteorological reports are not valid. Provided the aspects of the atmosphere were accurately analyzed, it was hoped hope that signs that can confirm or refute the existence of the global warming could be found.

Last year (2015), the students used the CanSat's geophysical and meteorological sensors for precise measurements at higher altitudes.

In 2016, the secondary mission was based on different dynamics and position measurements, 3D mapping and data communication. For the dynamic position analysis, acceleration was measured along the three axes (x, y, z). A 3axis compass was also used to determine the momentary position as accurately as possible, combined with real-time GPS (Global Positioning System) data. The CanSat assigned its location to all the data it measured. This location was completed with the altitude and the tilting data in comparison with the vertical state. These three measurements were processed by a program written in JavaScript, which can create an animation about the movements of the CanSat. The data are a basis for the educational outreach, which is based on a 3D map of the environment around the CanSat (figure 6).

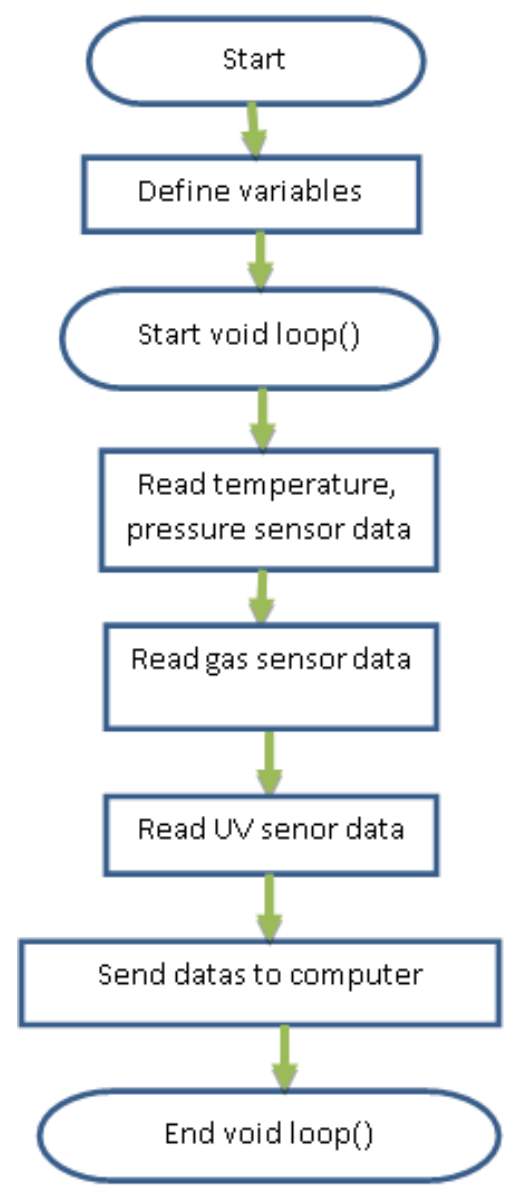

Figure 5. Flowchart of the CanSat 15 atmosphere command unit.

One of the objectives of the secondary mission was to successfully log the data obtained from the sensors not only on a ground unit via the RF transmitter, but also on a webserver (in a MySQL database) using a built-in GPRS module. Another aim, closely connected to the former was to draw a virtual track of the CanSat's descent. The last technical target was to back-up all the data on a micro SD (Secure Digital) card (aboard the CanSat) with an OpenLog unit. Uploading the data to the webserver was achieved using a small subsystem consisting of an Olimexino Nano GSM (Global System for Mobile Communications) data processing unit combined with a SIM800H quad-band GSM/GPRS module. This unit works on frequencies GSM850MHz and PCS1900MHz. SIM800H features GPRS multi-slot class 12/class 10 (optional) and supports the GPRS coding schemes CS-1, CS-2, CS-3 and CS-4. Basically, this circuit is the core item of the data processing plan, and it works in the following way: it collects the data received from the sensors and uploads it to a web page provided by the students. Since this is a complete subsystem, even in case of failure, it will not affect other parts of the secondary mission and it leaves more computing capacity for other tasks. [4] 


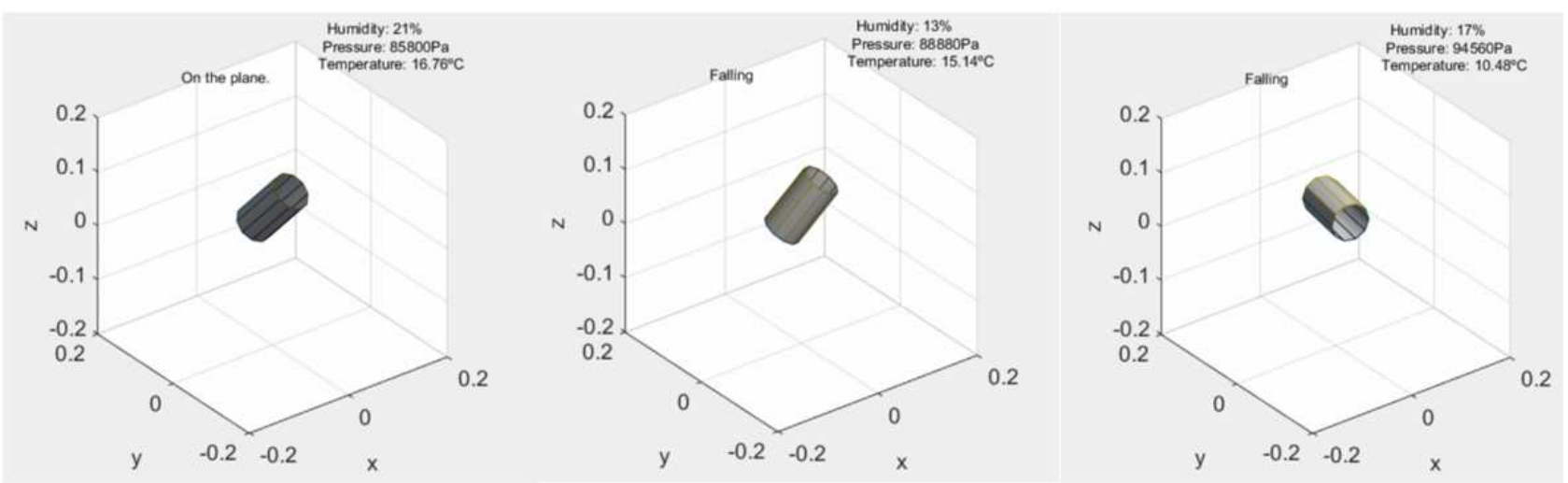

Figure 6. Animation of the CanSat falls with the pressure, humidity and temperature data.

Nevertheless, during the fall, the measured data were sent with a radio transmitter to the ground, and then they were uploaded to a server with the GPRS module. The server saved the received data in a MySQL database and immediately processed them on a webpage. On the page, the line of falling was illustrated in 3D based on information received from GPS, the incidence angle of CanSat from Gyro data, and the rate of fall based on accelerometer data.

Students were always amazed by how the professionals at ESA and NASA create fancy images or maps containing a lot of information from data obtained and transmitted back to a ground station by space telescopes. It remains interesting how one can map the surface of an unknown space object without having actually land any kind of equipment on it. An orbiting unit is enough to scan the surface, and even mountains, valleys and rivers can be drawn based on the obtained data. This interest determined the secondary mission to create a 3D map based on the position of the CanSat and pictures from a CMOS (complementary metal-oxide semiconductor) camera module with a resolution of $728 \times 488$ pixels.

The data visualization was based on a 3D map of the terrain beneath the flying unit that is created in Auto CAD 3DSMax. On this map, a visualization of the measured atmospheric features was presented along with the position and movements of the unit. Using the data obtained from the sensors, the height of the point was calculated compared to sea level. Furthermore, the exact coordinates were determined using the GPS data, the speed of the fall, acceleration of the CanSat and data measured by the gyro sensors. [4]

The CanSat started to collect data right at beginning of the descent. In this way, data of pressure and temperature readings were constantly being sent. From these measurements, the students calculated the parameters of the weather and displayed them on the 3D map. After the CanSat landing these measurements, data were processed in Wolfram Mathematica and Mathlab to create a falling simulation. The snapshots taken by a CMOS (complementary metal-oxide semiconductor) camera, due to the large quantity of data, were only saved to the SD card and were not transmitted to the ground station via the RF transmitter.
It was considered to design an efficient and safe recovery system. Likewise, an outer shell is another part of the secondary mission. The recovery system mainly consisted of the parachute. A lot of tests were carried out to define the right surface area of the parachute, as there is a multitude of unpredictable natural factors. Finally, it was decided to make three chutes from 6,8 and 12 isosceles acute triangles, and choose the most efficient according to the weather conditions. A canopy material was used, which is adequately strong and flexible. In order to design the parachute (figure 7), the students used some simple physics principles, which they have learned at Mechanics classes: Newtonians laws fall in the gravitational field, drag, etc.

$$
G=F \text { and } m \cdot g=\frac{1}{2} \rho A C_{d} v^{2}
$$

The following formula was used to determine the diameter (D) of the parachute:

$$
\mathrm{D}=\sqrt{\frac{8 \cdot m \cdot g}{\pi \cdot \rho \cdot C_{d} \cdot v^{2}}}
$$

Where:

m- total weight of body and parachute

g- acceleration of gravity, equal to $9.81 \mathrm{~m} / \mathrm{s}^{2}$

$\rho$ - the local density of the air $\left(\rho=1.22 \mathrm{~kg} / \mathrm{m}^{3}\right)$.

$\mathrm{C}_{\mathrm{d}^{-}}$the drag coefficient (for the semi-spherical parachute $\left.\mathrm{C}_{\mathrm{d}}=1,5\right)$

v- descent speed of the CanSat (the maximal speed reached during the fall is $\mathrm{v}=8 \mathrm{~m} / \mathrm{s}$ )

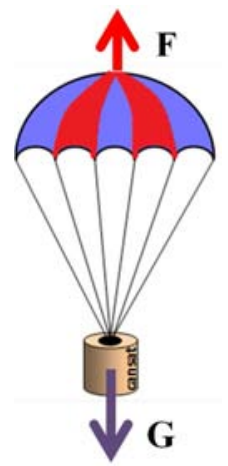

Figure 7. The structure of the CanSat parachute. 
For the shell of the CanSat, two materials were tested. One of the choices was the carbon-fiberglass, since it is a strong material and has a surprisingly good solidity. Moreover, it is flexible, within its breaking elongation limit, at the offload it gets back to the original shape. This feature changes depending on the change of the thickness of the material. It does not absorb humidity, it is non-flammable and heat insulator. Its only disadvantage was the price. Beside the carbon-fiberglass, a PLA (PolyLactic-Acid) was tested plastic as a possible raw material for the shell. Plastic was decided to be used because it is cheaper and more accessible than the carbon-fiberglass, and due to the highly customizable character of plastic a proper outer cover was made that withstands the forces appearing at the moment of impact with the ground. This year the CanSat's protection shell had two scopes. The first one was a straightforward one, it had to protect the main part of the electric circuits. In addition to this, a set of mini solar panels were attached to it. It was well thought to make it strong and light enough. First, the idea was making two different shells of which one supposed to be made of simple fiberglass and the other of vacuumed plastic. A 2-3 mm thick fiberglass shell was made and then 4 rows of solar panels were fixed on it.

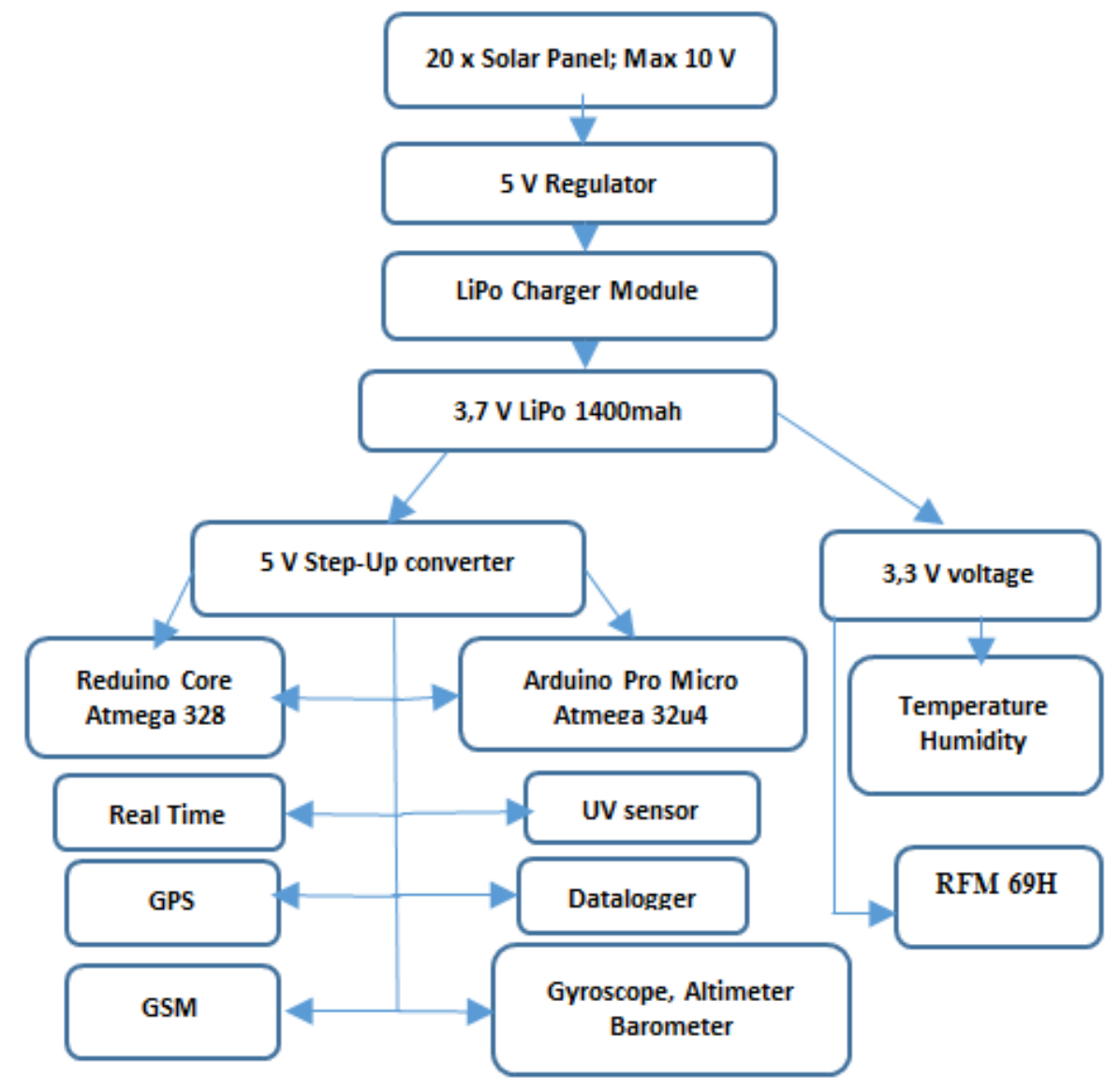

Figure 8. The diagram of the Miko-Cansat 16.

Two different, weather-related sensor units measured data: mean temperature, atmospheric pressure and humidity. The same unit, an HTU21D Digital Relative Humidity Sensor with Temperature Output, measured temperature and humidity. This sensor provided calibrated, linearized signals in digital, I2C format. Besides the low power consumption and fast response time another advantage of this sensor was that the resolution (both for RH and T) can be changed by command. Our pressure sensor, the LPS25H, was incorporated into the AltIMU-10 v4 unit. $[6,7]$

The LPS25H is an ultra-compact absolute piezoresistive pressure sensor. It includes a monolithic sensing element and an IC interface able to take the information from the sensing element and to provide a digital signal to the external world. An added advantage was that it had a high shock survivability of $10000 \mathrm{~g}$.

The AltIMU-10 v4 unit was also equipped with a threeaxis digital output gyroscope and an ultra-compact high performance e-Compass 3D accelerometer and 3D magnetometer module (LSM303D). The L3GD20H gyroscope was a low-power three-axis angular rate sensor. It included a sensing element and an IC interface able to provide the measured angular rate to the external world through digital interface (I2C Inter-Integrated Circuit, or SPISerial Peripheral Interface). The LSM303D was a system-inpackage featuring a 3D digital linear acceleration sensor and a 3D digital magnetic sensor.

The nine independent rotation, acceleration, and magnetic readings provided all the data needed to make an altitude and heading reference system (AHRS), and readings from the 
absolute pressure sensor can be easily converted to altitudes, giving a total of ten independent measurements (sometimes called 10DOF). With an appropriate algorithm, the microcontroller built-in device and the computer was able to use the data to calculate the orientation and height of the AltIMU board. [8]

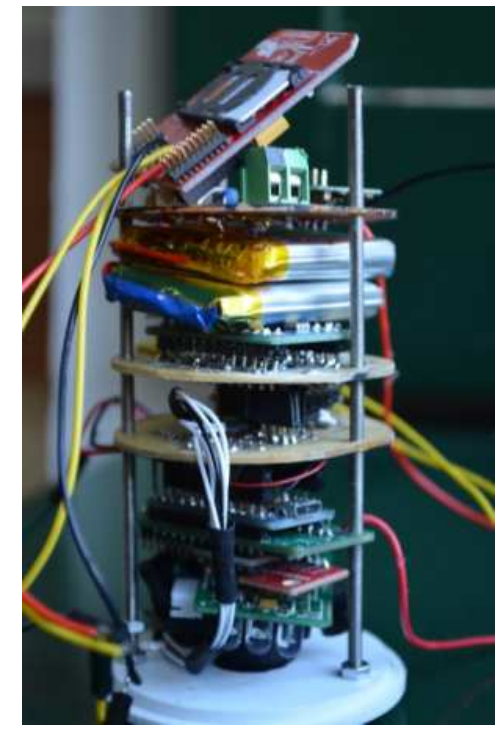

Figure 9. The Miko CanSat 16 unit prepared for testing.

The device was also equipped with a piezoelectric component to detect the moment when the CanSat lands. At the moment of landing, a small electrical tension was produced in the piezo element. The piezo is an electronic device that generates a voltage when it is physically deformed by a vibration, sound wave, or mechanical strain. If the sensor's output is stronger than a certain threshold, the board sends the string "Knock!" to the computer display over the serial port (figure 9).

An ADH-tech (Advanced Design House) sensor provided GPS data. The GP-735 is a slim, ultra-high performance, easy to use GPS smart antenna module designed with ubloc's latest 7th generation single chip. Another sensor (ML8511) measured UV (ultraviolet) intensity, whose value is then weighted according to the CIE Erythemal Action Spectrum (a standardized measure of human skin's response to different wavelengths of sunlight from UVB to UVA) giving us the UV index. The UV index is a number of a linear scale from zero to 11. The ML8511 sensor was currently used, however, several other types of sensors were also tested. Considering the low supply current $(300 \mathrm{~mA}$ in function and $0.1 \mathrm{~mA}$ in standby mode), the current sensor guarantees a long battery life. In addition, it operates perfectly between $-25^{\circ} \mathrm{C}$ and $75^{\circ} \mathrm{C}$, which is in accordance with atmospheric measurements. An Arduino microcontroller drove the completely measuring device with an appropriate programme written by the students.

\section{Conclusion}

The students are interested in this project since it is something new and exciting for them, which could help them discover the fascinating world of space science and technologies. Not only will the acquired knowledge and experiences help them in their daily lives but also in the future in their professional career. These contests offer a very good opportunity to improve the students' knowledge in transcurricular topics, they could combine physics and math skills with computer science, programming and engineering.

After every contest, the results are always applied in the teaching process. Therefore, a mini meteorological station was built using the CanSat components and air parameters are collected on a daily basis. A comparative meteorological (pressure, temperature, UV radiation, wind) map was created for the town along with a Launch Campaign site which is used during physics lessons (regarding topics such as thermodynamics, geography, and biology). In the preparation phase of this project, several 3D charts were made with the help of data collected while testing at Sugas-Hill, near the town, therefore these data can also be used.

There is a second level of the activity, which is carried out along with the planning, building and testing phase of CanSat. In this way, the public is informed regarding the most recent accomplishments of the project. Presentations are organized on special physics lessons at "Bod Péter" County Library, interactive workshops for primary school students (9-11 years old) during the Science Day or science camp; blogs are also run in three languages (Hungarian, Romanian and English). On these blogs, the students have the opportunity to publish articles, presenting details for all who are interested and to share information about the whole progress of the project. In addition, the school website is also a relevant platform for disseminating this project. Finally yet importantly, articles are also published in the school and local newspapers.

\section{Acknowledgements}

I would like to acknowledge the support of the Content Pedagogy Research Program (Project number 471027) of the Hungarian Academy of Sciences.

I would like to express my appreciation and thank my students from the Székely Mikó Science Club for their dedication, hard and persistent work, for the achievements within this project over the last five years.

\section{References}

[1] M. Pető "Experiments with Cansat"-ICPE-EPEC 2013 Active learning - in a changing world of new technologies; Editors: L. Dvořák, V. Koudelková; Prague, 2014, ISBN 978-80-7378266-5; pp. 766-774.

[2] M. Pető "Atmosphere physics in a soda can- CanSat 12" (Légkörfizika egy üdítős dobozban avagy CanSat 12) Conference book (in Hungarian language), editors: A. Juhász., T. Tél-A fizika, matematika és a müvészet találkozása az oktatásban, kutatásban, Eötvös Loránd University, Budapest, 2013, pp. 272-284; ISBN 978-963-284-346-9. 
[3] M. Pető, Robotics, Cansat, Arduino-Physics at Székely Mikó Science Club; Teaching Physics Innovatively New Learning Environments and Methods in Physics Education, Proceedings of the international conference Teaching Physics Innovatively (TPI-15) New Learning Environments and Methods in Physics Education Budapest, 17-19 August, editors: A. Király, T. Tél, 2015. ISBN 978-963-284-815-0; (pp. 169-174).

[4] M. Pető M. Space research and mini-satellites in secondary School, $3^{\text {rd }}$ International Conference on research, technology and Education of Space, H-Space 2017, Budapest, ISBN 978963-7367-12-0.

[5] The CanSat book- ESA, NAROM (Norwegian Centre for Space-related Education)-e-book.

[6] R. Pietraru. "10 projects with Arduino" (in Romanian language: 10 proiecte cu Arduino), Techno Media, Sibiu, 2015.

[7] Arduino and Robotics- lessons for beginners, (Curs Arduino si robotica- in Romanian language), Robofun, Bucharest, ISBN 978-606-616-167-1; 2015.

[8] R. Petrianu, A. Velcu: Basic knowledge to developing microcontroller-based devices (Elemente practice de baza in dezvoltarea sistemelor cu microprocesoare integrate- in Romanian language), Tehno Media, Sibiu, ISBN 978-606616-140-4; 2014.

[9] C. Mantea, M. Gabaret: Physics book for $10^{\text {th }}$ grade students; (in Hungarian language), Bucharest, Bic All, 2005.

[10] A. Bojtos: Sensors- Temperature sensors (in Hungarian language), Budapest, BME-MOGI, 2016. 